\title{
The role of serum tryptase in the diagnosis and monitoring of pediatric mastocytosis: a single-center experience
}

\author{
Magdalena Lange ${ }^{1}$, Agata Zawadzka², Stephanie Schrörs², Justyna Słomka², Hanna Ługowska-Umer ${ }^{1}$, \\ Bogusław Nedoszytko ${ }^{1}$, Roman Nowicki ${ }^{1}$
}

${ }^{1}$ Department of Dermatology, Venereology and Allergology, Medical University of Gdansk, Gdansk, Poland ${ }^{2}$ Medical Student Research Committee, Medical University of Gdansk, Gdansk, Poland

Adv Dermatol Allergol 2017; XXXIV (4): 306-312

DOI: https://doi.org/10.5114/ada.2017.69308

\begin{abstract}
Introduction: In children, cutaneous mastocytosis $(\mathrm{CM})$ is considered to be a benign disease associated with mast cell mediator-related symptoms. However, systemic mastocytosis (SM) and anaphylaxis may also occur. Since the basal serum tryptase (bsT) level reflects mast cell burden, its determination is recommended in the diagnosis and follow-up.

Aim: To compare clinical presentation and the course of mastocytosis in children with normal and clearly elevated bsT levels as well as to assess its usefulness in the diagnosis and monitoring of the course of the disease.

Material and methods: A retrospective analysis of 102 medical records of children with mastocytosis diagnosed and followed-up in the Gdansk Mastocytosis Center in 2014 was performed.

Results: Maculopapular CM (MPCM) was diagnosed in 91 (89.22\%) children, diffuse cutaneous mastocytosis (DCM) in 7 (6.86\%) and mastocytoma in 4 (3.92\%). The presence of flushing and bullous lesions was more frequent in children with bsT levels $>20 \mathrm{ng} / \mathrm{ml}$ in comparison with those who had bsT $\leq 20 \mathrm{ng} / \mathrm{ml}(p=0.002$ and $p=0.03$, respectively). Anaphylaxis occurred in 2 MPCM children with bsT levels in normal ranges. In all of the 3 children with persistently and clearly elevated bsT levels, bone marrow biopsy revealed no mast cells infiltrates corresponding to SM.

Conclusions: Although mastocytosis children with clearly elevated bST levels frequently develop mediator-related symptoms, the occurrence of anaphylaxis in this age group may be difficult to predict. In pediatric cases with suspected SM, the bsT level is one of the crucial parameters considered before the decision on bone marrow biopsy.
\end{abstract}

Key words: mastocytosis, serum tryptase, children, diagnosis.

\section{Introduction}

Mastocytosis is a rare heterogeneous disease characterized by a pathological proliferation and activation of morphologically and immunophenotypically abnormal mast cells (MCs) in various tissues, particularly in the skin (cutaneous mastocytosis - CM) and internal organs (systemic mastocytosis - SM) such as the bone marrow (BM), liver, spleen and the lymph nodes [1-3]. The diagnosis of SM is based on the World Health Organization (WHO) criteria [1-3]. The BM infiltration by MCs with presence of multifocal compact MCs greater than 15 MCs per cluster is a major criterion of SM. The minor criteria include: 1 . more than $25 \%$ of spindle-shaped MCs in BM smears, 2. an aberrant expression of CD25 and/or CD2 by BMMCs, 3. a detection of the D816V KIT mutation in BM or blood and 4. serum tryptase levels exceeding $20 \mathrm{ng} /$ $\mathrm{ml}$ (excluding patients who have clonal hematologic nonMCs lineage disease) [2, 3]. The presence of the major criterion and one minor criterion or at least three minor criteria is required for the diagnosis of SM [1-3].

In contrast to adults, the typical presentation of the disease in children is CM defined as MCs infiltration limited to the skin $[3,4]$. A recently published classification of CM distinguishes three major clinical manifestations: maculopapular CM (MPCM, traditionally named urticaria pigmentosa), diffuse cutaneous mastocytosis (DCM) and mastocytoma of the skin [4]. Diffuse cutaneous masto-

Address for correspondence: Magdalena Lange MD, PhD, Department of Dermatology, Venereology and Allergology, Medical University of Gdansk, 7 Dębinki St, 80-211 Gdansk, Poland, phone: +48 601378 899, e-mail: m.lange@gumed.edu.pl

Received: 18.02.2016, accepted: 19.06.2016. 
cytosis is a rare but the most severe form of CM characterized by generalized erythema and thickened skin, frequently associated blisters at the onset of the disease. Involvement of the entire or almost entire skin is a characteristic feature of DCM. In MPCM, skin symptoms consist of disseminated brown or red and often oval lesions of different sizes (polymorphic variant) or homogeneous, small macules and/or papules (monomorphic variant) [4]. Mechanical irritation of skin lesions leads to the release of MCs mediators and thus to reddening and urticarial swelling. This reaction, known as the Darier's sign, is typical for all forms of CM and plays an important role in the initial clinical diagnosis [4-7]. However, it is of a great importance to elicit Darier's sign gently in small children with intensive skin lesions, because stroking a CM lesion can provoke mast cell mediator-related symptoms such as flushing and systemic hypotension [4].

The course of pediatric mastocytosis is usually benign and transient [4-6]. However, a systemic involvement and fatal outcome have been reported in isolated cases [7-9]. A systematic review of pediatric mastocytosis cases published between 1950 and April 2014 indicates that fatal outcome was reported in 18 (2.9\%) cases including DCM $(n=5), \operatorname{MPCM}(n=4), \operatorname{SM}(n=2)$, SM with associated hematological non-mast cell disease $(n=1)$, mast cell sarcoma $(n=4)$ and mast cell leukemia $(n=2)$ [10]. Consequently, the total blood count, basal serum tryptase (bsT) level and abdomen ultrasound are recommended in all mastocytosis children as the first step in the diagnostic algorithm [11-14]. Determination of bsT levels is of a major importance because it has been considered as the indicator of the total body MCs burden [14]. Furthermore, the bsT level is the only minor WHO criterion of SM, which can be easily determined using peripheral blood. In order to check other WHO criteria for SM, it is necessary to perform BM biopsy [1-3]. The suspicion of SM arises in children with serum bsT levels persistently $>100 \mathrm{ng} / \mathrm{ml}$ or rising with time [11-13]. Recently published studies indicate that the KIT mutation can be found in peripheral blood in the majority of SM cases [15-17]. Therefore, the determination of this mutation in the blood should be considered in the diagnostic work-up for pediatric mastocytosis, particularly in cases with suspected SM.

Regardless of the form of the disease, the majority of mastocytosis patients suffer from various symptoms due to the release of MCs mediators including flushing, itching, blistering, diarrhea, abdominal pain, vomiting, hypotension, headache and anaphylaxis among others [1-7]. Both an extensive cutaneous involvement and clearly elevated bsT level have been considered as a risk factor for severe mediator-related symptoms in children [18, 19].

\section{Aim}

The aim of our study was to compare the clinical presentation of mastocytosis in children with bsT levels
$20 \mathrm{ng} / \mathrm{ml}$ and in those with clearly elevated bsT levels $>20 \mathrm{ng} / \mathrm{ml}$. For this reason, subforms of CM and the frequency of mast cell mediator-related symptoms including anaphylaxis were compared in both subgroups of children. We also aimed to assess the usefulness of bsT levels determination in the diagnosis and follow-up of the disease. Therefore, we analyzed in detail clinical data of 13 children with bsT levels $>20 \mathrm{ng} / \mathrm{ml}$ and discussed indications to perform a BM biopsy in pediatric mastocytosis on the basis of our own experience.

\section{Material and methods}

A retrospective analysis of 102 medical records of children with mastocytosis diagnosed in 2014 in the Gdansk Mastocytosis Center was performed. The study group consisted of both first-time pediatric dermatology patients $(n=24)$ and followed-up ones $(n=78)$. In all cases the medical history, physical examination with provoking Darier's sign, histopathological examination of the skin lesions (both Giemsa staining and anti-c-kit CD117 staining were used), determination of the bsT level, peripheral blood analysis with differential, serum levels of transaminases and abdomen ultrasound were performed. The BsT levels were determined by a commercial fluorescent enzyme immunoassay (ImmunoCAP Tryptase System, Phadia, Uppsala, Sweden and Thermo Fisher Scientific Inc.). In all cases, bsT levels were measured in basic clinical conditions. Apart from bsT levels other minor criteria of SM were not evaluated.

Following recent European Competence Network on Mastocytosis (ECNM) recommendations on CM classification, we qualified small lesions as monomorphic MPCM and larger or various sized plaque lesions as polymorphic MPCM [4]. The term mastocytoma was used only for the solitary skin lesion. Diffuse cutaneous mastocytosis was recognized when the entire or almost entire skin was involved and fulfilled the characteristics described above [4]. A BM histology was performed in 3 cases when systemic involvement was highly suspected [12].

\section{Statistical analysis}

The results were expressed as the percentage of patients, means and standard deviations (SD). The differences concerning the percentage values between groups were measured using $\chi^{2}$ test. $P<0.05$ was considered significant. Statistica 10.0 PL (StatSoft, Inc.) software was used.

\section{Results}

A group of 102 children aged from 3 month to 14 years (mean age: \pm SD: $2.5 \pm 3$ years) with various clinical forms of mastocytosis was examined in 2014. The study group embraced 58 males and 44 females (the male-tofemale ratio was 1.3). Maculopapular CM was diagnosed 
Table 1. Mast cell mediator-related symptoms in children with cutaneous mastocytosis

\begin{tabular}{|c|c|c|c|c|c|c|c|}
\hline \multirow[t]{3}{*}{ MRS } & \multirow{2}{*}{\multicolumn{2}{|c|}{$\begin{array}{c}\text { Total } \\
N=102\end{array}$}} & \multirow{2}{*}{\multicolumn{2}{|c|}{$\begin{array}{c}\mathrm{bsT} \leq 20 \mathrm{ng} / \mathrm{ml} \\
N=89\end{array}$}} & \multirow{2}{*}{\multicolumn{2}{|c|}{$\begin{array}{c}\text { bsT }>20 \mathrm{ng} / \mathrm{ml} \\
N=13\end{array}$}} & \multirow[t]{3}{*}{$P$-value } \\
\hline & & & & & & & \\
\hline & $n$ & $\%$ & $n$ & $\%$ & $n$ & $\%$ & \\
\hline Pruritus & 55 & 53.9 & 47 & 52.8 & 8 & 61.5 & 0.55 \\
\hline Abdominal pain & 39 & 38.2 & 37 & 41.6 & 2 & 15.4 & 0.07 \\
\hline Bullae/vesicles & 35 & 34.3 & 27 & 30.3 & 8 & 61.5 & 0.03 \\
\hline Flushing & 27 & 26.5 & 19 & 21.3 & 8 & 61.5 & 0.002 \\
\hline Diarrhea & 16 & 15.7 & 15 & 16.9 & 1 & 7.7 & 0.40 \\
\hline Dyspnea & 7 & 6.9 & 6 & 6.7 & 1 & 7.7 & 0.90 \\
\hline Headache & 6 & 5.9 & 5 & 5.6 & 1 & 7.7 & 0.77 \\
\hline Vomiting & 4 & 3.9 & 4 & 4.5 & 0 & 0 & 0.44 \\
\hline Hypotension & 2 & 1.96 & 2 & 2.2 & 0 & 0 & 0.59 \\
\hline Anaphylaxis & 2 & 1.96 & 2 & 2.2 & 0 & 0 & 0.59 \\
\hline
\end{tabular}

MRS - mast cell mediator-related symptoms, bsT-basal serum tryptase level.

in 91 of 102 (89.22\%) children, DCM in 7 (6.86\%) and mastocytoma in 4 (3.92\%). Bone marrow biopsy was performed in 3 children with a clearly increased bs T level. None of them met the major criterion of SM. In the remaining patients, the BM study was not indicated and was not performed. No clinically significant abnormalities in the complete blood count with differential were found in all examined children. The mean monitoring period in a subgroup of followed-up mastocytosis children $(n=78)$ was $3.5 \pm 2$ years, whereas in those with bsT levels $\leq 20 \mathrm{ng} / \mathrm{ml}$ and those with bsT levels $>20 \mathrm{ng} / \mathrm{ml}$, it was $4.5 \pm 2$ years and $3.5 \pm 2$ years, respectively. There was no fatal outcome in our series of followed-up mastocytosis children.

In our study group, there were $89(87.25 \%)$ children with bsT levels $\leq 20 \mathrm{ng} / \mathrm{ml}$ and $13(12.75 \%)$ children with elevated bsT levels $>20 \mathrm{ng} / \mathrm{ml}$. In all mastocytosis children, the mean bsT at the first visit was $10.83 \pm 18.24$ $\mathrm{ng} / \mathrm{ml}$, whereas in those with bsT levels $\leq 20 \mathrm{ng} / \mathrm{ml}$ and those with bsT levels $>20 \mathrm{ng} / \mathrm{ml}$, it was $5.44 \pm 3.71 \mathrm{ng} / \mathrm{ml}$ and $46.85 \pm 32.09 \mathrm{ng} / \mathrm{ml}$, respectively. All children with DCM had bsT levels $>20 \mathrm{ng} / \mathrm{ml}$, whereas in all children with mastocytoma, this protease was in normal ranges (5-11 ng/ml).

In our series, the most common MCs mediator-related symptom was pruritus, which occurred in 55 (53.9\%) children, followed by abdominal pain (38.2\%), bullous lesions (34.3\%) and flushing (26.5\%) (Table 1). Bullous lesions or vesicles were present in 29 MPCM and in 6 DCM cases. Generalized bullae appeared in 2 children with DCM, whereas in the remaining 4 DCM children and 29 MPCM ones, bullous lesions/vesicles were limited to the involved skin. Table 1 shows the frequency of particular MCs mediator-related symptoms in mastocytosis children with bsT levels $\leq 20 \mathrm{ng} / \mathrm{ml}$ and those with bsT levels $>20 \mathrm{ng} / \mathrm{ml}$. Statistical analysis of the obtained data re- vealed that children with bsT levels $>20 \mathrm{ng} / \mathrm{ml}$ suffered from flushing and bullous eruption more frequently than those with bsT levels $\leq 20 \mathrm{ng} / \mathrm{ml}$ ( $p=0.002$ and $p=0.03$, respectively). The only $2(1.96 \%)$ anaphylactic reactions in our series were recorded in 2 girls with MPCM involving $25 \%$ and $10 \%$ of body surface area (BSA), respectively. In both cases, bsT levels were in normal ranges $(5.8 \mathrm{ng} / \mathrm{ml}$ and $3.5 \mathrm{ng} / \mathrm{ml}$, respectively) and episodes of anaphylaxis were once-in-a-lifetime reactions provoked by ketamine and an unknown factor.

The clinical presentation and the course of the disease were analyzed in detail in the subgroup of $13 \mathrm{pa}$ tients with bsT levels $>20 \mathrm{mg} / \mathrm{ml}$ temporally or persistently (Tables 2 and 3). In this subgroup, there were 7 (53. 85\%) children with DCM and 6 (46.15\%) with MPCM. The presence of bullous lesions or vesicles was found in 6 (85.7\%) DCM cases and in 2 (33.3\%) MPCM cases (Table 2). Four DCM children presented with pronounced and hemorrhagic blisters corresponding to large hemorrhagic bullous variant, whereas in 2 DCM ones, small vesicles periodically occurred, typically for the infiltrative small vesicular variant of the disease. Apart from diffuse erythroderma, which was found in all DCM children, infiltrative nodules were present in 2 of them. The polymorphic variant of MPCM was found more frequently than the monomorphic form (4 cases and 2 cases respectively). Both pruritus and flushing occurred more frequently in DCM children than in MPCM ones (pruritus in 5 (71.4\%) DCM and in $3(50 \%)$ MPCM cases, whereas flushing in 6 (85.7\%) DCM and in 2 (33.8\%) MPCM cases) (Table 3).

In 13 children with bsT levels $>20 \mathrm{ng} / \mathrm{ml}$, the levels of this marker were determined at the first visit and during the follow-up period ranging from 1 year to 7 years (Table 3). BsT levels declined over time in 6 children while in 5 children they remained similar and in 2 they have been increasing over time. In 5 children, including 4 with DCM 
Table 2. Cutaneous manifestation of mastocytosis in children with a serum tryptase level $>20 \mathrm{ng} / \mathrm{ml}$

\begin{tabular}{|c|c|c|c|c|c|c|c|c|c|}
\hline No. & Age of onset & Gender & First skin lesions & $\mathrm{SI} \%$ & $\begin{array}{l}\text { Darier's } \\
\text { sign }\end{array}$ & Bullae/vesicles & $\begin{array}{c}\text { Age at the } \\
\text { last visit } \\
\text { [years] }\end{array}$ & SR & $\begin{array}{c}\text { Type of cutaneous } \\
\text { mastocytosis }\end{array}$ \\
\hline 1 & 3 months & M & Erythema, bullae & 90 & Yes & Yes, located & 6 & Yes & DCM \\
\hline 2 & 6 months & $M$ & Extensive bullae & 95 & Yes & Yes, generalized & 9 & Yes & DCM \\
\hline 3 & Congenital & $\mathrm{F}$ & $\begin{array}{l}\text { Brownish } \\
\text { macules }\end{array}$ & 10 & Yes & No & 5 & No & $\begin{array}{l}\text { Polymorphic } \\
\text { MPCM }\end{array}$ \\
\hline 4 & 3 months & M & $\begin{array}{c}\text { Brownish } \\
\text { macules }\end{array}$ & 80 & Yes & Yes, located & 7 & No & $\begin{array}{l}\text { Polymorphic } \\
\text { MPCM }\end{array}$ \\
\hline 5 & 4 months & $\mathrm{F}$ & $\begin{array}{l}\text { Brownish } \\
\text { macules }\end{array}$ & 60 & Yes & No & 3 & No & $\begin{array}{l}\text { Polymorphic } \\
\text { MPCM }\end{array}$ \\
\hline 6 & 7 months & $\mathrm{F}$ & Erythema, bullae & 90 & Yes & Yes, located & 8 & Yes & DCM \\
\hline 7 & 3 months & M & $\begin{array}{l}\text { Erythema, } \\
\text { vesicles }\end{array}$ & 90 & Yes & Yes, located & 6 & Yes & DCM \\
\hline 8 & 5 months & M & $\begin{array}{l}\text { Brownish } \\
\text { macules }\end{array}$ & 15 & Yes & Yes, located & 7 & No & $\begin{array}{l}\text { Polymorphic } \\
\text { MPCM }\end{array}$ \\
\hline 9 & 12 years & $\mathrm{F}$ & $\begin{array}{l}\text { Brownish } \\
\text { macules }\end{array}$ & 10 & Yes & No & 15 & No & $\begin{array}{l}\text { Monomorphic } \\
\text { MPCM }\end{array}$ \\
\hline 10 & 5 months & M & $\begin{array}{l}\text { Erythema, } \\
\text { vesicles }\end{array}$ & 90 & Yes & Yes, located & 2 & No & DCM \\
\hline 11 & 3 months & $\mathrm{F}$ & $\begin{array}{l}\text { Diffuse } \\
\text { erythema }\end{array}$ & 90 & Yes & No & 3 & No & DCM \\
\hline 12 & 2 months & $M$ & Extensive bullae & 90 & Yes & Yes, generalized & 2 & No & DCM \\
\hline 13 & 6 years & M & $\begin{array}{l}\text { Brownish } \\
\text { macules }\end{array}$ & 20 & Yes & No & 17 & Yes & $\begin{array}{c}\text { Monomorphic } \\
\text { MPCM }\end{array}$ \\
\hline
\end{tabular}

${ }^{*} S 1 \%$ - percentage of the skin involved; SR - tendency towards spontaneous regression of skin lesions. DCM - diffuse cutaneous mastocytosis, MPCM - maculopapular cutaneous mastocytosis.

Table 3. Extra-cutaneous features of mastocytosis in children with a basal serum tryptase level $>20 \mathrm{ng} / \mathrm{ml}$

\begin{tabular}{cccccccccccc}
\hline No. & Age at visit 1 & $\begin{array}{c}\text { Monitoring } \\
\text { period } \\
\text { [years] }\end{array}$ & T1 & T2 & T3 & T4 & T5 & BM & Organomegaly & MRS \\
\hline 1 & 15 months & 5 & 20 & 21 & 12 & 5 & ND & ND & Hepatomegaly & P, F \\
\hline 2 & 17 months & 7 & 106 & 39 & 28 & 16 & 20 & ND & Hepatomegaly & P, F, AP \\
\hline 3 & 18 months & 3 & 23 & 16 & ND & ND & ND & ND & No & No \\
\hline 4 & 24 months & 5 & 20 & 26 & 19 & 22 & ND & ND & No & P \\
\hline 5 & 24 months & 1 & 28 & 22 & 29 & ND & ND & ND & No & P \\
\hline 6 & 36 months & 5 & 30 & 23 & 22 & 11 & ND & ND & No & $P$ \\
\hline 7 & 24 months & 4 & 28 & 19 & 24 & ND & ND & ND & No & $P, F$ \\
\hline 8 & 14 months & 6 & 13 & 21 & 14 & ND & ND & ND & No & $P$ \\
\hline 9 & 14 years & 1 & 31 & 35 & ND & ND & ND & ND & No & $F$ \\
\hline 10 & 11 months & 1 & 80 & 82 & ND & ND & ND & ND & No & $P, F$ \\
\hline 11 & 20 months & 2 & 63 & 70 & 63 & 82 & ND & Normal & Hepatomegaly & $F, D y$ \\
\hline 12 & 18 months & 1 & 65 & 92 & 117 & 96 & ND & Normal & No & $F$ \\
\hline 13 & 12 years & 5 & 99 & 46 & ND & ND & ND & Normal & No & $F, A P$, \\
\hline
\end{tabular}

$T$ - basal serum tryptase level at visit 1, 2, 3, 4, 5, BM - bone marrow biopsy, MRS - mast cell mediator-related symptoms ( $P$ - pruritus, $F$ - flushing, $A P$-abdominal pain, Dy-dyspnea, Di-diarrhea, $\mathrm{H}$ - headache). ND-not done. 
and 1 with MPCM, bsT levels were $>60 \mathrm{ng} / \mathrm{ml}$ at the first visit. In 3 children with persistently and clearly elevated bsT levels, a BM biopsy was performed (Table 3). None of these children met the major criterion of SM. A transient hepatomegaly without impairment of the organ function was recorded in 3 DCM cases. A tendency towards spontaneous regression of skin lesions was observed in 5 (38.5\%) of 13 children with bsT levels > $20 \mathrm{ng} / \mathrm{ml}$ and corresponded to the decline in bsT levels in all cases (Table 3). There were no cases of complete remission in this subgroup.

\section{Discussion}

The exact values of mastocytosis prevalence in Middle Europe has not been reported but it is estimated to be $0.005-0.01 \%$ or $0.5-1$ per 10,000 [1]. Herein, we have managed to present the results of a retrospective analysis of a large group of 102 children with mastocytosis, examined within 1 year because we are a referral center for Polish patients suffering from this disease. It has been estimated that in pediatric mastocytosis, the male-tofemale ratio is 1.4 , similarly as it was found in our series [10]. A systematic review of literature indicates that approximately $90 \%$ of children develop initial skin lesions within the first 2 years of life [7, 10]. This may explain the young age of children in our series, which was 2.5 years.

Results of our study indicate that MPCM was the most common form of CM in children, followed by DCM and mastocytoma. The frequency of particular forms of CM in pediatric mastocytosis has been clarified by Méni et al. on the basis of a literature review of 1747 cases [10]. Urticaria pigmentosa, recently termed MPCM, was recognized in $75 \%$ of cases, mastocytoma in $20 \%$ and DCM in 5\% [10]. In comparison with these data, we found a higher frequency of MPCM (89.22\%) and DCM (6.86\%) and a lower frequency of mastocytoma (3.92\%). These discrepancies may occur due to the fact that we diagnose the majority of the most severe cases in our country as a referral center.

Both adults and children with mastocytosis may experience MCs mediator-related symptoms which are usually provoked by exposure to heat, cold, sudden changes of temperature, trauma of skin lesions, emotional stress, infections, drugs (NSAIDs, opioids, muscle relaxants, anesthetics among others), dental procedures, vaccines, surgery and endoscopic procedures [6, 7, 18, 19]. In our study group, the most common symptom related to MCs mediators was pruritus (54\%), followed by abdominal pain, bullous lesions and flushing. The review of the literature confirms that pruritus is the most common mediator-related symptom in children (48\%) [10]. Moreover, it has been reported that the frequency of bullous lesions (34\%) and flushing (24.5\%) is very similar to our findings [10]. The comparison of the frequency of MCs mediator-related symptoms between two subgroups of our patients revealed that children with bsT levels over $>20 \mathrm{ng} / \mathrm{ml}$ suffered from flushing and bullous eruption more frequently than those with bsT levels $\leq 20 \mathrm{ng} / \mathrm{ml}$. The results obtained confirm our previous observations that significantly higher mean bsT levels were determined in CM children with flushing and bullous lesions than in those without these symptoms [7].

Current studies show that anaphylaxis occurs in 1.5$9 \%$ of pediatric mastocytosis cases [10, 18-22]. In our series, severe anaphylactic reactions appeared in 2 (1.96\%) children who presented with MPCM and had bsT levels in normal ranges. It has been reported that increased bsT levels and extensive skin involvement are predictors of severe, even life-threatening MCs activation events [19, 20]. Alvarez-Twose et al. found severe symptoms requiring hospitalization in 12 of 111 children who presented with extensive skin lesions involving over $90 \%$ of BSA and calculated that cut-off value for bsT level likely to predict the need for management in an intensive care unit is $30.8 \mathrm{ng} / \mathrm{ml}$ [19]. In contrast to these results, none of 6 children with bsT levels $>30 \mathrm{ng} / \mathrm{ml}$ experienced lifethreatening complications in our series. Altogether, these findings suggest that anaphylaxis in mastocytosis children may be difficult to predict.

The BsT level is considered to be the essential "preinvasive' screen parameter in patients with mastocytosis because it reflects the total body MCs burden $[1,13,14]$. However, it can be increased in cases of the severely impaired renal function, associated hematological diseases and during anaphylactic reactions [14]. Therefore, it is essential to collect serum samples for bsT level measurements at least $48 \mathrm{~h}$ after complete resolution of all anaphylaxis-related symptoms [1]. It is noteworthy that in our series, all children with DCM had bsT levels > $20 \mathrm{ng} / \mathrm{ml}$, whereas in all children with mastocytoma, this parameter was in normal ranges $(5-11 \mathrm{ng} / \mathrm{ml})$. These findings confirm a previously reported observation that an increase in bsT levels may be associated with extensive skin involvement without underlying SM [7, 19, 23-25]. It is of a great importance to take into consideration the extent and intensity of skin lesions when we assess the diagnostic value of bsT levels in particular patients [23-25].

The exact frequency of SM in pediatric mastocytosis remains unknown [6, 10, 26-29]. However, published data indicate that children with clearly elevated bsT levels face an increased risk of SM development [7-9, 26, 27]. Therefore, we have been paying particular attention to a careful diagnosis and follow-up of 13 patients with bsT levels $>20 \mathrm{mg} / \mathrm{ml}$ temporally or persistently. In this subgroup, there were 7 children with DCM and 6 with MPCM. DCM children presented with a large hemorrhagic bullous variant, infiltrative small vesicular variant of the disease and erythroderma with small nodular lesions. In our series, there were no pachydermic and pseudoxanthomatous forms of DCM which were reported in isolated cases [30, 31]. As a result of a widespread and 
heavy MCs load in the entire skin, DCM children usually develop various mediator-related symptoms [23, 24, 32]. Our DCM children also suffered from itching, flushing, bullous lesions, dyspnea and abdominal pain. Bullae may occur in all forms of CM, particularly in infants and tend to cease at the age of 1 or 2 years [4, 7, 23, 24]. The appearance of bullous lesions is attributed to serine proteases including chymase and tryptase released from MCs [32, 33]. Subepidermal blistering within lamina lucida was demonstrated by histopathology and antigen mapping in 1 DCM child [32]. In our series, the polymorphic form of MPCM, which is considered to be specific for pediatric mastocytosis, was found more frequently than the monomorphic form of MPCM typical for adults [4].

The diagnostic approach to childhood-onset mastocytosis has been still under discussion [6, 11-13, 28, 29]. The decision on BM biopsy to obtain samples for checking all SM criteria other than the bsT level is the most important because a BM biopsy is an invasive procedure, which usually requires general anesthesia or sedation in children. Although the frequency of anesthetic procedures to elicit anaphylactic episodes in mastocytosis is low, they must be managed as risk procedures [34]. Therefore, we support the opinion that a BM biopsy should be performed only in selected cases if there is a suspicion of SM or another hematological neoplasm [11-13]. The BM biopsy has been recommended in children with bsT levels persistently $>100 \mathrm{ng} / \mathrm{ml}$ or rising with time, clinically significant abnormalities in the peripheral blood and organomegaly [6, 11-13, 28, 29]. It is noteworthy that even if a KIT mutation is detectable in the skin or in the blood or serum bsT is moderately increased, then a BM biopsy is not required in children [13]. In our series, there were 5 children with bsT levels $>60 \mathrm{ng} / \mathrm{ml}$ at the first visit in which we weighed up whether BM biopsy should be performed. In 2 of them (patient no. 2 and 13), bsT levels showed the evident tendency to decrease during followup and there were no clinically significant abnormalities in laboratory tests. Since in patient no. 2, the skin lesions involved approximately $90 \%$ of BSA, we assessed that the increased bsT level is associated with a heavy, widespread MCs burden in the skin and consequently a BM biopsy was not performed. In patient no. 13, a BM biopsy was done, although the bsT level partially decreased, because we concluded that it does not correspond to the low extent of MPCM. The BM biopsy was also performed in 2 DCM children (patient no. 11 and 12) with bsT levels increasing over the monitoring period. The decision on BM biopsy in patient no. 10 with DCM will depend on the bsT level and laboratory test results at the next visit. Finally, none of our patients met the major criterion for SM. Consequently, our results suggest that there were no SM cases in our study group. However, morphology and immunophenotype of MCs as well as D816V KIT mutation in blood or BM would be necessary to rule out SM completely. All children from the study group are followed-up in our center. If bsT increases significantly or other signs and symptoms of the disease progression occur, minor criteria are going to be checked.

Regarding the young age of children in our study group and a relatively short monitoring period we decided to evaluate data concerning the course of the disease only in a subgroup of 13 children with bsT $\geq 20 \mathrm{ng} / \mathrm{ml}$. It is a common knowledge that in pediatric mastocytosis the regression rate increases with age and a complete spontaneous remission can be expected in the pubertal age $[4,6,10]$. Partial remission was found in 5 of 13 children with a follow-up period ranging from 4 to 7 years. There were no cases of complete remission. It was partially due to the young age of children in this subgroup (mean age: 3.5 years). Generally, it is very difficult to estimate the frequency of a complete regression of $\mathrm{CM}$ in children on the basis of literature because of small number of reports focused on this aspect, various lengths of monitoring periods in particular studies as well as a small number of children included in these studies [10, 35]. For example Uzzan et al. observed 68\% of complete regression cases in a group of 15 children at a median follow-up of 20 years [35]. We hope to continue to follow-up children with mastocytosis in our center to clarify a true tendency towards spontaneous regression of skin lesions in the pediatric form of the disease.

\section{Conclusions}

Childhood-onset mastocytosis is usually a benign disease characterized by a wide range of cutaneous manifestations and associated with MCs mediatorrelated symptoms [4, 6, 28, 29]. Results of our study show that both anaphylaxis and systemic involvement are rare findings in pediatric patients with mastocytosis. Nevertheless, the review of the literature and authors' personal experience indicate that the risk of SM and lifethreatening episodes should be taken into consideration in the management of pediatric mastocytosis $[6,11,18$, 19]. Therefore, the use of the appropriate diagnostic algorithm, follow-up and prophylactic treatment with antihistamines and rescue subcutaneous epinephrine in the treatment of anaphylaxis are recommended [6, 11, 13]. From both the diagnostic and prognostic point of view, the bsT level has still remained the crucial parameter reflecting pediatric mastocytosis severity.

\section{Acknowledgments}

Funding sources: Grant 02-0066/07/253 from the Polish Ministry of Science and Higher Education.

\section{Conflict of interest}

The authors declare no conflict of interest. 


\section{References}

1. Valent P. Mastocytosis: a paradigmatic example of a rare disease with complex biology and pathology. Am J Cancer Res 2013; 3: 159-72.

2. Akin C, Valent P. Diagnostic criteria and classification of mastocytosis in 2014. Immunol Allergy Clin North Am 2014; 34 207-18.

3. Horny HP, Akin C, Metcalfe DD, et al. Mastocytosis (mast cell disease). World Health Organization (WHO). Classification of tumors: pathology and genetics. In: Tumours of haematopoietic and lymphoid tissues. Swerdlow SH, Campo E, Harris NL (eds). IARC Press, Lyon 2008; 54-63.

4. Hartmann K, Escribano L, Grattan C, et al. Cutaneous manifestations in patients with mastocytosis: Consensus report of the European Competence Network on Mastocytosis; the American Academy of Allergology, Asthma \& Immunology; and the European Academy of Allergology and Clinical Immunology. J Allergy Clin Immunol 2016; 137: 35-45.

5. Lange M, Nedoszytko B, Górska A, et al. Mastocytosis in children and adults: clinical disease heterogeneity. Arch Med Sci 2012; 8: 533-41.

6. Castells M, Metcalfe DD, Escribano L. Diagnosis and treatment of cutaneous mastocytosis in children. Am J Clin Dermatol 2011; 12: 259-70.

7. Lange M, Niedoszytko M, Renke J, et al. Clinical aspects of paediatric mastocytosis: a review of 101 cases. J Eur Acad Dermatol Venereol 2013; 27: 97-102.

8. Mamadeo KM, Wolgast L, McMahon C, Cole PD. Systemic mastocytosis in a child with $\mathrm{t}(8 ; 21)$ acute myeloid leukemia. Pediatr Blood Cancer 2011; 57: 684-7.

9. Yabe M, Masukawa A, Kato S, et al. Systemic mastocytosis associated with $\mathrm{t}(8 ; 21)$ acute myeloid leukemia in a child: detection of the D816A mutation of KIT. Pediatr Blood Cancer 2012; 59: 1313-6.

10. Méni C, Bruneau S, Georgin-Lavialle L, et al. Paediatric mas tocytosis: a systematic review of 1747 cases. Br J Dermatol 2015; 172: 642-51.

11. Heide R, Beishuizen A, de Groot H, et al. Mastocytosis in children: a protocol for management. Pediatr Dermatol 2008; 25: 493-500.

12. Lange $M$, Ługowska-Umer $H$, Niedoszytko $M$, et al. Diagnosis of mastocytosis in children and adults in daily clinical practice. Acta Derm Venereol 2016; 96: 292-7.

13. Valent P, Escribano L, Broesby-Olsen S, et al. Proposed diagnostic algorithm for patients with suspected mastocytosis; a proposal of the European Competence Network on Mastocytosis. Allergy 2014; 69: 1267-74.

14. Valent P, Akin C, Escribano L, et al. Standards and standardization in mastocytosis: consensus statements on diagnostics, treatment recommendations and response criteria. Eur J Clin Invest 2007; 37: 435-53.

15. Kristensen T, Vestergaard H, Bindslev-Jensen C, et al. Sensitive KIT D816V mutation analysis of blood as a diagnostic test in mastocytosis. Am J Hematol 2014; 89: 493-8.

16. Jara-Acevedo M, Teodosio C, Sánchez-Muňoz L, et al. Detection of the KIT D816V mutation in peripheral blood of systemic mastocytosis: diagnostic implications. Mod Pathol 2015; 28: 1138-49.

17. Broesby-Olsen S, Oropeza AR, Bindslev-Jensen C, et al. Recognizing mastocytosis in patients with anaphylaxis: value of KIT D816V mutation analysis of peripheral blood. J Allergy Clin Immunol 2015; 135: 262-4.
18. Matito A, Carter M. Cutaneous and systemic mastocytosis in children: a risk factor for anaphylaxis? Curr Allergy Asthma Rep 2015; 15: 22.

19. Alvarez-Twose I, Vano-Galvan S, Sanchez-Munoz L, et al. Increased serum baseline tryptase levels and extensive skin involvement are predictors for the severity of mast cell activation episodes in children with mastocytosis. Allergy 2012; 67: 813-21.

20. Barnes M, Van L, DeLong L, Lawley LP. Severity of cutaneous findings predict the presence of systemic symptoms in pediatric maculopapular cutaneous mastocytosis. Pediatr Dermatol 2014; 31: 271-5.

21. Brockow K, Jofer C, Behrendt H, Ring J. Anaphylaxis in patients with mastocytosis: a study on history, clinical features and risk factors in 120 patients. Allergy 2008; 63: 226-32.

22. Gonzalez de Olano D, de la Hoz B, Nunez-Lopez R, et al. Prevalence of allergy and anaphylactic symptoms in 210 adult and pediatric patients with mastocytosis in Spain: a study of the Spanish network on mastocytosis (REMA). Clin Exp Allergy 2007; 37: 1547-55.

23. Lange $M$, Niedoszytko $M$, Nedoszytko $B$, et al. Diffuse cutaneus mastocytosis: analysis of 10 cases and a brief review of the literature. J Eur Acad Dermatol Venereol 2012; 26: 1565-71.

24. Heide R, Zuidema E, Beishuizen A, et al. Clinical aspects of diffuse cutaneous mastocytosis in children: two variants. Dermatol 2009; 219: 309-15.

25. Brockow K, Akin C, Huber M, et al. Assessment of the extent of cutaneous involvement in children and adults with mastocytosis: relationship to symptomatology, tryptase levels, and bone marrow pathology. J Am Acad Dermatol 2003; 48: 508-16.

26. Shaffer HC, Parsons DJ, Peden DB, Morrell D. Recurrent syncope and anaphylaxis as presentation of systemic mastocytosis in a pediatric patient: case report anf literature review. J Am Acad Dermatol 2006; 54 (5 Suppl): S210-3.

27. Gogia A, Sharawat SK, Kumar R, et al. Systemic mastocytosis associated with childhood acute myeloid leukemia. J Pediatr Hematol Oncol 2013; 35: 163-4.

28. Fried AJ, Akin C. Primary mast cell disorders in children. Curr Allergy Asthma Rep 2013; 13: 693-701.

29. Frieri M, Queershi M. Pediatric mastocytosis: a review of the literature. Pediat Aller Imm Pul 2013; 26: 175-80.

30. Sanchez-Salas MP, Lazaro AC, Martin J, et al. Atypical pachydermatous cutaneous course of mastocytosis. Actas Dermosifil 2007; 98: 707-10.

31. Srivastava N, Chand S, Singh S. Pseudoxanthomatous mastocytosis. Int J Dermatol 2008; 47: 50-1.

32. Kleewein K, Lang R, Diem A, et al. Diffuse cutaneous mastocytosis masquering as epidermolysis bullosa. Pediatr Dermatol 2011; 28: 720-5.

33. Metcalfe DD. Mast cells and mastocytosis. Blood 2008; 112: 946-56.

34. Matito A, Morgado JM, Sanchez-Lopez P, et al. Management of anesthesia in adult and pediatric mastocytosis: a study of the Spanish Network on Mastocytosis (REMA) based on 726 anesthetic procedures. Int Arch Allergy Immunol 2015; 167: 47-56.

35. Uzzan A, Maric I, Noel P, et al. Pediatric-onset mastocytosis: a long term clinical follow-up and correlation with bone marrow histopatology. Pediatr Blood Cancer 2009; 53: 629-34. 